\title{
Mental comparisons involving abstract attributes
}

\author{
ALLAN PAIVIO \\ University of Western Ontario, London, Ontario, Canada N6A $5 C 2$
}

\begin{abstract}
Adult subjects in two experiments were presented pairs of stimuli that differed in varying degree on an abstract semantic attribute, and were required to choose the one with the higher value on the given dimension. Subjects in Experiment 1 chose the more pleasant member of a pair of pictures, concrete nouns, or abstract nouns. Those in Experiment 2, presented a pair of pictures or concrete nouns, chose the one whose referent had the higher monetary value. Theoretical interest centered on the effects of semantic distance, stimulus mode, and individual differences in imagery and verbal ability on choice time. In both experiments, response times (1) decreased with increases in semantic distance, (2) were faster for pictures than words (and for concrete than abstract words in Experiment 1), and (3) were faster for high- than for lowimagery participants. The results are completely consistent with a dual-coding (image vs. verbal) interpretation: Pleasantness and value, though conceptually abstract, are attributes of things rather than words, and they are accordingly represented in and processed by a system specialized for dealing with nonverbal information.
\end{abstract}

This study investigated the role of verbal and nonverbal symbolic processes in mental comparisons involving ordered information on "abstract" semantic attributes. The specific attributes involved were pleasantnessunpleasantness and monetary value. These dimensions are abstract in the sense that they are not directly represented in perceptual stimuli in the same way as are such "concrete" attributes as size, shape, and color. More rigorously stated, attribute values for the more abstract dimensional concepts are less consistently correlated with specific perceptual attributes than is the case for more concrete concepts.

The above distinction is the basis of a theoretical controversy. Paivio (1975, in press $-a$, in press $-b$ ) interpreted and predicted various effects in mental comparison tasks involving concrete dimensions, such as size, in terms of a dual-coding theory. The theory postulates independent but interconnected verbal and nonverbal symbolic systems which are differentially accessible to verbal and nonverbal stimuli and have different structural and functional characteristics. The verbal system is more directly accessed by linguistic stimuli such as printed words; the nonverbal system, by nonverbal stimuli such as pictures. The verbal system is specialized for representing and processing linguistic information, whereas the nonverbal system is specialized for representing and processing perceptual information concerning concrete objects and events. The latter is an analog system in the sense that its representational

This research was supported by Grant A0087 from the National Research Council of Canada. Requests for reprints should be sent to Allan Paivio, Department of Psychology, University of Western Ontario, London, Ontario, Canada N6A 5C2. units and structures in long-term memory "contain" information that bears a continuous (analog) relation to the perceptual information aroused directly by the perceptual objects themselves. The perceptual nature of the representations is reflected most obviously in the conscious experience of imagery, hence the designation of the system as an imagery or image-generating system. It is assumed, however, that the system can be functional without its activity necessarily being manifested in reportable imagery.

According to this theory, the image system contains the information on which perceptual memory comparisons are based. Thus, verbal stimuli such as animal names (e.g., Moyer, 1973) first activate representation in the verbal system. These in turn arouse appropriate representations in the image system, which are compared with respect to the relevant attribute (e.g., size). The theory accounts for various facts (see Paivio, 1975, 1978): the symbolic distance effect (faster reaction times with larger differences on the dimension involved); faster reaction times for pictures than words even when the pictures do not directly represent perceptual differences on the relevant dimension; a Stroop-like conflict when the perceptual size difference between a pair of pictured objects is incongruent with memory size; equivalent reaction times for comparisons between and within conceptual categories; a reversal of the pictures vs. words effect when the comparison involves a verbal characteristic such as pronounceability; and so on.

The controversy arises in connection with comparisons on more abstract dimensions. Banks and Flora (1977) presented subjects with pairs of names or pictures of animals and asked them to choose the member of each pair that was "smarter" (or "dumber"). They found that comparison time was faster for pictures 
than for words and concluded that this contradicted the dual-coding model, which they interpreted as predicting faster processing for words than pictures when the comparison was on abstract dimensions. Kerst and Howard (1977) reached a similar conclusion in regard to the symbolic distance effect, which they investigated for such abstract attributes as ferocity of animals as well as concrete ones such as size. They reasoned that, if the abstract dimension yielded a symbolic distance effect, "the distinction between imagery and verbal processes, in terms of analog vs. discrete representations (Paivio, 1975), would have to be revised (p. 229)." In fact, they found that response time decreased as symbolic distance increased in the case of both abstract and concrete judgments.

The predictions and conclusions in the above studies were based on reasonable interpretations of the dualcoding approach in regard to the concrete-abstract functional distinction and the presumed analog nature of imaginal representations. These interpretations need to be tempered by qualifications that accompanied the original theoretical statements, although the relevant aspects of dual-coding theory also required elaboration and modification in order to be consistent with the results of the above studies as well as with those arising from the present research.

Consider, first, the abstract-concrete functional distinction. The assumption as originally stated was that the image system is specialized for dealing with concrete objects and events, whereas the verbal system is relatively more efficient in dealing with abstract information (Paivio, 1971). This was, however, accompanied by the qualification that the proposed distinction cannot be a rigid one, inasmuch as abstract ideas can be concretized or instantiated as images and images can be relatively abstract or schematic in the sense that they lack detail (Paivio, 1971, p. 27; Paivio, 1977, pp. 51.52). This qualification was motivated by various empirical observations, but its ultimate usefulness depends on more rigorous notions about the nature of abstract informa. tion and more precise statements concerning the conditions under which imagery plays an important role in processing such information. In the present context, these issues translate into the interpretation of abstractnessconcreteness of dimensional attributes of concepts, and whether such attributes are likely to be associated with information in the imagery or the verbal system. It has been argued that such concrete dimensions as size are stored somehow in the imagery system, and that comparisons on those dimensions therefore will be faster with pictures than with words (Paivio, 1975). In the case of more abstract dimensions, the relative contributions of imaginal and verbal codes and the consequent picture-word predictions would depend on the extent to which such dimensions are interpreted as being attributes of things rather than of the language that describes them. Intelligence and ferocity, for ex- ample, are inferences based on the concrete behavior of living things, and it could be argued that our knowledge concerning the attributes is based on perceptual memories of such behaviors. To the extent that this is so, it follows that the imagery system plays a primary role in comparisons involving the dimensions, and comparison times would be expected to be faster with pictures than with words as stimuli. Of course, this would simply be a circular argument unless supported by other independent evidence that the imagery system is involved in such comparisons. One purpose of the present research was to obtain such additional evidence.

The above arguments are also relevant to the dualcoding assumption concerning the analog nature of imagery. Specifically, if such dimensions as ferocity are attributes of concrete things, then they should be represented in some analog form in the image system. Kerst and Howard (1977) recognized such a possibility, although in their interpretation imagery played a more secondary role than is intended here. Specifically, they found that comparisons on abstract dimensions were generally slower than those on the more concrete ones, and they accordingly suggested that abstract information, though stored in some nonimaginal form, may be converted to a metaphorical analog image for purposes of comparison. The suggestion remained speculative, however, particularly since abstractnessconcreteness was confounded with other attributes (e.g., familiarity) in their study. Moreover, even assum. ing that the imagery system is involved, the symbolic distance effect remains a theoretical puzzle in the case of the attributes investigated by Kerst and Howard. The reason is that the distance effect implies that the underlying perceptual variable must be unidimensional, which is inconsistent with the observation that abstract attributes of things are not correlated with simple visual dimensions. What, then, is the nature of the continuous analog information that can yield a symbolic distance effect in such cases? A tentative answer is that the analog information is carried by nonvisual sensorymotor processes that are closely associated with nonverbal visual representations in long-term memory. This suggestion will be elaborated on in the General Discussion section of this paper, where it can be put in the context of the results of the present experiments.

These experiments, completed before the publication of studies by Banks and Flora (1977) and Kerst and Howard (1977), were designed specifically to provide evidence on the relative involvement of imaginal and verbal processes in comparisons involving abstract dimensions. Two experiments investigated the symbolic distance effect for the dimension of pleasantnessunpleasantness and monetary value. These dimensions were chosen because the comparison task can be done with either pictures or words as stimuli. In the case of pleasantness, pictures, concrete words, and abstract words were used, so the concreteness dimension varied 
over three levels. Three logical possibilities, with different theoretical implications, could be evaluated in regard to the effects of the concreteness attribute on pleasantness judgments. First, affective quality might be associated more closely with words. If so, the comparisons should be faster with words than with pictures. Second, the affective information might be tied more closely to the concrete referents than to words, in which case the comparisons should be faster with pictures than with words. Moreover, they should be faster for concrete than abstract words because the referent images are more directly available in the concrete case. Finally, the affective information might be in a completely different semantic system, equally accessible to pictures and words. If so, the reaction time should not differ for the different classes of stimuli. A similar logic applies in the case of monetary-value judgments with pictures and their concrete-noun labels as stimuli.

Each experiment also included measures of individual differences in imagery ability as a second empirical indicator of the involvement of the imagery system. High-imagery subjects should be generally faster than low-imagery subjects only to the extent that imagery is crucial to performance on the comparison task. A measure of associational fluency was also included as a measure of verbal ability, with theoretical implications paralleling those for imagery. Prior research involving a relatively concrete comparison task revealed significant effects only for imagery ability (Paivio, 1978). In the present case, because of the greater abstractness of the task, one might expect verbal ability as well as imagery to be relevant.

\section{EXPERIMENT 1}

The first experiment involved comparisons on pleasantness. The dimension was varied for experimental subjects on the basis of pleasantness ratings of a larger pool of items obtained from an independent group of subjects. The ratings were obtained only for concrete and abstract words, with picture pleasantness being inferred from their concrete-noun labels.

\footnotetext{
Method

Pleasantness ratings. A sample of 352 nouns was drawn from the Paivio, Yuille, and Madigan (1968) norms so that the entire range of imagery and concreteness values was represented. These, along with a different set of 297 "pictureable" words, were rated for pleasantness by 48 university undergraduates using a 7-point scale, where 1 corresponded to very unpleasant and 7 to very pleasant. The ratings had been obtained in the context of other research. Since other comparison studies in the present series have involved ratings of concrete words on 9-point scales (e.g., size in Paivio, 1975), 314 such words were re-rated on 9-point scales by a new sample of 47 undergraduates. The two sets of mean pleasantness scores for the 314 nouns correlated .94 , indicating high intergroup reliability. The pleasantness differences for the pairs used in the present experiment were based on the 7-point-scale norms. These are uncorrelated with concreteness $(r=-.01)$ and imagery $(r=.02)$ in the 352 word sample from Paivio et al. (1968).
}

Experimental pairs. The pairs were constructed from highly concrete and highly abstract (low-imagery) items so that the pleasantness differences varied equally for the concrete and abstract pairs. The concrete items were ones for which corresponding pictures were available. Each concrete noun was the dominant label for its pictorial referent, according to normative data (Paivio, Note 1). The concreteness and imagery means, respectively, were 6.69 and 6.52 for the concrete nouns drawn from Paivio et al. (1968) and 2.83 and 3.91 for the abstract nouns. Eighteen pairs of each type were constructed so that six pairs were represented in each of three pleasant/unpleasant pseudoratio differences of $1.5,2.5$, and 3.5. The corresponding mean arithmetic differences were $1.66,3.12$, and 4.11 . The latter is more justified on the grounds of measurement theory, but the scale choice is of little practical consequence in the present case since the ratio and arithmetic differences were highly correlated (.94 and .90 in the case of concrete and abstract pairs, respectively). The mean arithmetic difference was slightly higher overall for concrete than for abstract pairs (3.06 vs. 2.84 ), but not enough to account for the experimental effects (see below). The pairs are presented in Table 1. The picture pairs corresponded to the concrete-noun pairs (no independent pleasantness ratings were obtained for the pictures). Examples of picture pairs and their corresponding concrete-noun pairs are presented in Figure 1. The 18 items of a list were arranged into four different random orders and the 18 items were repeated with their left-right position reversed in the second half. Thus, each experimental list consisted of 36 pairs. The serial position of the picture pairs was the same as those of their corresponding concrete-noun pairs, and the abstract-noun list paralleled the others with respect to pleasantness ratios of pairs in the different positions.

Individual difference tests. Imagery ability was measured by three spatial manipulation (figural transformation) tests. These were Space Relations (Form A) of the Differential Aptitude Test battery (Bennett, Seashore, \& Wesman, 1947), a shortened version (cf. Ernest \& Paivio, 1969) of the Minnesota Paper Form Board (MPFB) (Likert \& Quasha, 1941), and Block Visualization (Guilford, 1967). The last is a "pure" mental imagery test in the sense that the required visual transformations are generated entirely in response to verbally stated descriptions and questions. The subject is asked to think of a cube of a particular size and color, which is sliced up into smaller cubes. Then they are asked how many of the smaller cubes have two colored surfaces, how many have three, and so on. This is an old mental imagery problem which Guilford extended into a quantifiable form. The three tests were selected because they are objective and have been shown to load on a common figural transformational ability factor (Guilford, 1967). They were atso moderately intercorrelated in a cumulative sample of subjects that had participated in a series of mental comparison experiments, including the present ones (see Paivio, 1978).

Verbal ability was measured by an associative fluency test that required subjects to write as many different associations as they could in a $1-$ min period to each of four concrete and four abstract nouns. The test has been found to correlate with other verbal ability tests (Paivio, 1971, p. 496).

Procedure. The procedure was similar to that used previously for size comparisons (Paivio, 1975). The word pairs, typed in capitals, were presented by means of a Gerbrands two-channel tachistoscope to subjects who sat with their hands positioned on two response keys. They understood from prior instructions that they were to press the key on the side corresponding to the more pleasant of the two items on a card. Both speed and accuracy were emphasized. Each pair was exposed for a maximum of $5 \mathrm{sec}$. A trial was terminated by the subject's keypress which stopped a Hunter Model 120A Klockounter that had started when the card was exposed. The intertrial interval lasted about $15 \mathrm{sec}$, during which time the experimenter recorded the reaction time for a trial and changed the stimulus for a new trial. 
Table 1

Concrete- and Abstract-Noun Pairs Used in Experiment 1, with Mean Pleasantness Ratings in Parentheses

\begin{tabular}{cllll}
\hline $\begin{array}{c}\text { Difference } \\
\text { Ratio* }\end{array}$ & \multicolumn{3}{c}{ Abstract } \\
\hline & FACTORY-BUCKLE & $(2.27)-(3.69)$ & ECONOMY-HOPE & $(3.75)-(5.81)$ \\
& CACTUS-SCORPION & $(3.71)-(2.21)$ & DUTY-EXHAUSTION & $(3.75)-(2.29)$ \\
1.5 & WAGON-STRAWBERRY & $(3.81)-(5.67)$ & ROBBERY-DIFFUSION & $(1.94)-(3.35)$ \\
& FIREPLACE-BARREL & $(5.77)-(3.98)$ & SENSATION-DIRECTION & $(6.06)-(4.49)$ \\
& HAMMER-APPLE & $(3.52)-(5.50)$ & PERJURY-COMBUSTION & $(2.06)-(3.27)$ \\
& PEACH-BOWL & $(5.67)-(3.96)$ & FREEDOM-AFTERLIFE & $(6.52)-(4.63)$ \\
& HARP-DEVIL & $(5.54)-(2.02)$ & REMINDER-RHEUMATISM & $(3.88)-(1.53)$ \\
& WITCH-MOUNTAIN & $(2.42)-(5.65)$ & POVERTY-NECESSITY & $(1.60)-(3.94)$ \\
2.5 & SNAKE-OASIS & $(2.35)-(5.60)$ & DESTRUCTION-OBEDIENCE & $(1.58)-(3.91)$ \\
& DAFFODIL-RRUTCH & $(5.56)-(2.23)$ & MIRACLE-CRISIS & $(5.75)-(2.06)$ \\
& BULLET-PIANO & $(2.23)-(5.54)$ & SHAME-SOUL & $(1.85)(-04)$ \\
& EYE-SPIDER & $(5.73)-(2.67)$ & HEAVEN-WELFARE & $(6.27)-(2.44)$ \\
& KU KLUX KLAN-BABY & $(1.40)-(5.69)$ & EMBEZZLEMENT-LOYALTY & $(1.96)-(6.02)$ \\
& BED-MOSQUITO & $(5.96)-(1.75)$ & JUSTICE-BETRAYAL & $(5.71)-(1.52)$ \\
3.5 & ROSE-HANDCUFFS & $(6.00)-(1.88)$ & ENGAGEMENT-HOMICIDE & $(4.81)-(1.35)$ \\
& EXECUTIONER-BUTTERFLY & $(1.46)-(5.77)$ & SICKNESS-FESTIVITY & $(1.67)-(5.92)$ \\
& FLOWER-NOOSE & $(5.88)-(1.52)$ & KNOWLEDGE-TROUBLE & $(6.15)-(1.75)$ \\
& GUN-DOVE & $(2.15)-(6.04)$ & AGONY-TRUCE & $(1.35)-(4.90)$ \\
\hline
\end{tabular}

*The corresponding mean arithmetic differences are 1.66, 3.12, and 4.11.

A trial was preceded by a spoken "ready" signal. The experimental trials were preceded by six practice trials with pairs that were not used in the experiment. Each subject received only one kind of material, with subjects being rotated through the three stimulus conditions in the order of their appearance in the laboratory. Different subgroups received the different random orders of each list.

The subjects returned about 1 week after the experiment to complete the individual differences test battery.

Subjects. The subjects were 48 introductory psychology students who volunteered for the experiment to fulfill a course requirement. Sixteen subjects served in each stimulus condition.

\section{Results and Discussion}

Subjects' responses were scored as correct or incorrect according to the normative pleasantness differences. Error rates were generally low, averaging $2.8 \%, 3.6 \%$, and $3.8 \%$ for pictures, concrete words, and abstract words, respectively. They ranged from $0 \%$ to $19.4 \%$ for individual subjects. Errors also varied with symbolic

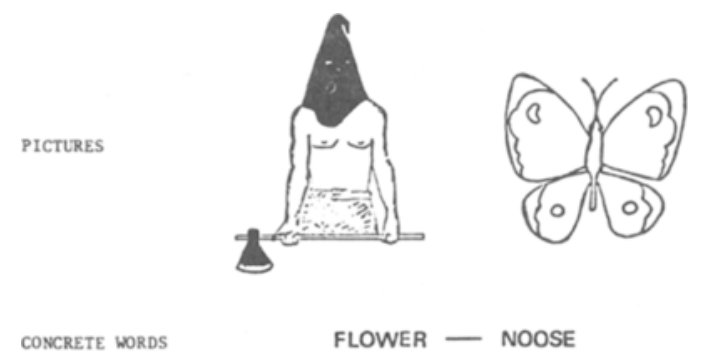

ABSTRACT WORDS GESTIVITY - SICKNESS

Figure 1. Examples of pairs of pictures, concrete words, and abstract words differing in rated pleasantness (Experiment 1). distance, the overall percentages being $7.5 \%, 1.9 \%$, and $1.0 \%$ for the $1.2,2.5$, and 3.5 differences, respectively. The analyses were performed on the correct reaction times, the means $(\overline{\mathrm{R}} \overline{\mathrm{T}})$ of which are plotted for each condition in Figure 2.

The data were analyzed by analysis of variance, with stimulus mode and ratio difference as between- and within-subjects factors, respectively. Both effects were highly significant, with no interaction. As can be seen in Figure $2, \overline{\mathbf{R}} \overline{\mathrm{T}}$ increased systematically as the size of the difference decreased $[F(2,47)=46.9, p<.001]$, reflecting the typical symbolic distance effect. This effect holds regardless of whether differences are scaled as ratios or arithmetic differences. Thus, the correlations of $\overline{\mathbf{R}} \overline{\mathbf{T}}$ scores for pairs with the pair ratio and arithmetic difference scores, respectively, were -.50 , and -.68 in the case of pictures, -.46 , and -.63 in the case of concrete words, and -.66 and -.75 in the case of abstract words. The arithmetic differences seems to be the better predictor, although not significantly so in any instance.

The times also increased from pictures, to concrete words, to abstract words $[F(2,47)=9.96, p<.001]$. Analyses of the simple effects showed that all of the differences between stimulus types were significant $[F(1,30) \geqslant 4.64, p<.05]$. Note in particular that there was no overlap in $\overline{\mathrm{RT}}$ s for concrete and abstract words. That is, the $\overline{\mathrm{RT}}$ for abstract pairs differing most on pleasantness was slower on the average than the $\bar{R} \bar{T}$ for concrete pairs differing least on pleasantness. Thus, the fact that overall pleasantness difference was slightly greater for concrete than abstract pairs cannot account for the concreteness effect on RT. These results are consistent with the hypothesis that the affective judg. ments are based on representations corresponding to 


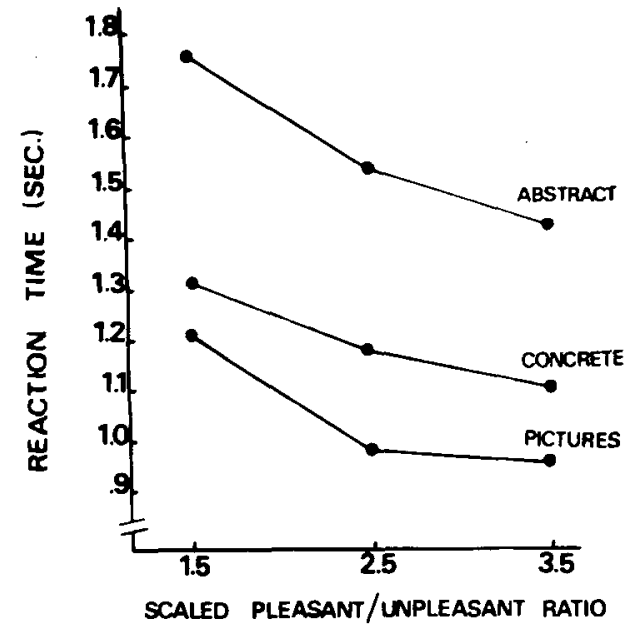

Figure 2. Mean reaction times for pleasantness comparisons for three types of stimuli as a function of ratio differences on the pleasantness scale. The corresponding mean arithmetic differences are $1.66,3.12$, and 4.11 .

referent objects or situations, which are more directly accessible to pictures than words and, within words, more accessible to concrete than abstract words. In terms of dual-coding theory, the data are consistent with the view that affective information is represented in the nonverbal symbolic system.

Individual differences. As in previous related studies (e.g., Paivio, in press-a, in press-b), imagery ability scores were calculated by transforming the subjects' scores on the MPFB, space relations, and block visualization into standard scores and then averaging over the three tests. Complete data were available for 45 subjects. These were divided at the median into high- and lowimagery groups. The same was done with the subject's total scores over concrete and abstract stimulus words on the verbal associative fluency test. The reaction time data were then analyzed by a four-way analysis of variance, with stimulus type, imagery ability, verbal ability, and ratios as factors. Unequal numbers of subjects in the cells were adjusted by the method of unweighted means (Winer, 1971). The effect of stimulus type and ratios was highly significant, as in the above analysis based on all 48 subjects. The interest here centers on the individual differences.

The analysis revealed a highly significant main effect for imagery ability $[F(1,33)=9.35, p<.005]$, with high imagers being generally faster than low imagers. The effect of verbal ability approached significance $[F(1,33)=3.85, p=.06]$. The only other significant effect was the interaction of the two abilities $[F(1,33)=$ $4.45, \mathrm{p}<.05]$, which is plotted in Figure 3 . It can be seen that the effect is attributable largely to the fast reaction times among subjects who scored high on both abilities. Thus, the effect of imagery ability was greater when verbal ability was high than when it was low. Reciprocally, verbal ability was effective only when imagery ability was high.
The triple interaction involving the two abilities and stimulus attribute was not significant $[F(2,33)=1.65]$. Nonetheless, examination of the data indicated that the double interaction of the two ability variables was attributable entirely to words, particularly abstract words. With pictures, high imagers were generally faster than low imagers, but there was no apparent effect of verbal ability regardless of imagery level.

The interaction of abilities differed from the results obtained in experiments involving memory size differences (e.g., Paivio, 1978). The latter showed main effects of imagery, no effects of the verbal ability measure, and no interaction. Thus, several studies were consistent in providing evidence for the role of imagery ability in comparison tasks, but verbal associative ability was implicated only in the pleasantness comparisons and even then only in interaction with imagery ability.

It should be noted that none of the interactions qualified the symbolic distance effect; it was reliable over different subgroups of subjects as well as item types. Moreover, comparisons were faster for pictures than for words at all symbolic distances and all subject groups, indicating its generality over different sets of pairs and subjects.

Finally, the main effects of the two abilities were generally confirmed by correlational analyses, although none of the individual $r$ values reaches significance. For pictures, subjects given concrete words, and abstract, respectively, the rs between overall $\overline{\mathrm{RT}}$ (collapsing over symbolic distance) and imagery ability were -.23 , -.25 , and -.27 . The corresponding rs with verbal ability were $.23,-.35,-.33$. Note that the correlations are consistently in the right direction (negative) in the case of imagery ability, but are so only for word stimuli in the case of verbal ability.

Replication experiment with concrete and abstract words. A modified replication was carried out with words only, primarily in order to control attributes that were confounded with concreteness in the original experiment. The concrete nouns tended to be higher than abstract in both meaningfulness and frequency. Since meaningfulness values were not available for many of the words, it was impractical to attempt to partial out its effect statistically. Accordingly, six concrete and

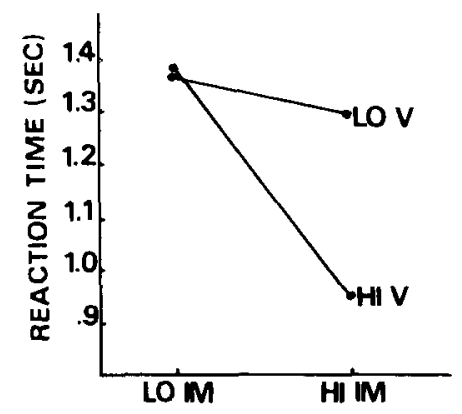

Figure 3. Effect of individual differences in imagery and verbal ability on reaction time for pleasantness comparisons. 
Table 2

Mean Attribute Values of the Pleasantness-Matched Concrete (C) and Abstract (A) Nouns Used in the Replication of Experiment 1

\begin{tabular}{|c|c|c|c|c|c|c|}
\hline \multicolumn{2}{|c|}{ Word } & \multirow{2}{*}{$\begin{array}{c}\text { Pleasantness } \\
2.21 \\
2.32\end{array}$} & \multirow{2}{*}{$\begin{array}{c}\text { Concreteness } \\
6.93 \\
3.72\end{array}$} & \multirow{2}{*}{$\begin{array}{c}\text { Imagery } \\
6.27 \\
3.37\end{array}$} & \multirow{2}{*}{$\begin{array}{c}\text { Meaningfulness } \\
6.00 \\
6.00\end{array}$} & \multirow{2}{*}{$\begin{array}{c}\begin{array}{c}\text { Thorndike- } \\
\text { Lorge } \\
\text { Frequency }\end{array} \\
3 \\
9\end{array}$} \\
\hline $\begin{array}{l}\text { scorpion } \\
\text { malady }\end{array}$ & $\begin{array}{l}\text { (C) } \\
\text { (A) }\end{array}$ & & & & & \\
\hline $\begin{array}{l}\text { tweezers } \\
\text { friction }\end{array}$ & $\begin{array}{l}\text { (C) } \\
\text { (A) }\end{array}$ & $\begin{array}{l}3.06 \\
3.00\end{array}$ & $\begin{array}{l}6.93 \\
4.26\end{array}$ & $\begin{array}{l}6.57 \\
4.33\end{array}$ & $\begin{array}{l}5.80 \\
5.28\end{array}$ & $\begin{array}{l}1 \\
9\end{array}$ \\
\hline $\begin{array}{l}\text { hammer } \\
\text { errand }\end{array}$ & $\begin{array}{l}\text { (C) } \\
\text { (A) }\end{array}$ & $\begin{array}{l}3.52 \\
3.52\end{array}$ & $\begin{array}{l}6.96 \\
4.21\end{array}$ & $\begin{array}{l}6.73 \\
4.27\end{array}$ & $\begin{array}{l}6.92 \\
6.48\end{array}$ & $\begin{array}{l}34 \\
20\end{array}$ \\
\hline $\begin{array}{l}\text { microscope } \\
\text { satire }\end{array}$ & $\begin{array}{l}\text { (C) } \\
\text { (A) }\end{array}$ & $\begin{array}{l}4.25 \\
4.33\end{array}$ & $\begin{array}{l}7.00 \\
2.33\end{array}$ & $\begin{array}{l}6.57 \\
3.37\end{array}$ & $\begin{array}{l}5.48 \\
5.64\end{array}$ & $\begin{array}{l}9 \\
7\end{array}$ \\
\hline $\begin{array}{l}\text { car } \\
\text { soul }\end{array}$ & $\begin{array}{l}\text { (C) } \\
\text { (A) }\end{array}$ & $\begin{array}{l}5.04 \\
5.04\end{array}$ & $\begin{array}{l}7.00 \\
1.87\end{array}$ & $\begin{array}{l}6.87 \\
2.13\end{array}$ & $\begin{array}{l}6.38 \\
6.40\end{array}$ & $\begin{array}{l}\text { AA } \\
\text { AA }\end{array}$ \\
\hline $\begin{array}{l}\text { baby } \\
\text { justice }\end{array}$ & $\begin{array}{l}\text { (C) } \\
\text { (A) }\end{array}$ & $\begin{array}{l}5.69 \\
5.71\end{array}$ & $\begin{array}{l}6.90 \\
2.18\end{array}$ & $\begin{array}{l}6.70 \\
3.60\end{array}$ & $\begin{array}{l}7.04 \\
6.60\end{array}$ & $\begin{array}{r}\mathbf{A A} \\
\mathbf{A}\end{array}$ \\
\hline
\end{tabular}

Note-The standard deviations of the pleasantness ratings ranged from 1.15 to 1.54 .

six abstract items were selected so that mean pleasantness varied in approximately equal steps and so that the pleasantness values were closely matched across concrete and abstract sets. The concrete and abstract items were also matched as closely as possible on Thorndike-Lorge frequency and on meaningfulness (Paivio et al., 1968). The items and their attribute values are presented in Table 2.

Lists of 15 concrete and 15 abstract pairs were constructed by pairing each item with every other one within each set. Symbolic distance varied over five levels of ordinal difference, as in the Kerst and Howard (1977) study. The pairs were randomly arranged into separate concrete and abstract lists, with the provision that the attribute-matched pairs occupied identical positions in each list. Subjects were given two trials with each list, with half the participants receiving the concrete list first and half receiving the abstract material first. Otherwise, the procedure was identical to the one used in the main experiment. Twenty introductory psychology students volunteered for the experiment in order to fulfill a course requirement.

The analyses were again based on mean correct responses for each participant, for each ordinal difference (the pattern of results was unchanged with errors included in the analysis). The results yielded highly significant main effects for concreteness $[F(1,19)=$ $19.63, p<.001]$ and symbolic distance $[F(4,76)=$ $10.37, \mathrm{p}<.001]$. The $\overline{\mathrm{R}} \mathrm{T}$ was faster for concrete pairs $(\bar{X}=1.002 \mathrm{sec})$ than for abstract pairs $(\overline{\mathrm{X}}=1.216)$, and $\mathrm{RT}$ decreased as symbolic distance increased (1.205, $1.152,1.129,1.055$, and $1.005 \mathrm{sec}$ ). These main effects clearly replicated the results of the main experiment. In addition, however, the replication experiment showed an interaction of Concreteness by Distance $[\mathrm{F}(4,76)=4.54$, $\mathrm{p}<.01$ ] . Examination of $\overline{\mathrm{R}} \overline{\mathrm{T}} \mathrm{s}$ indicated that the symbolic distance effect was stronger and more regular for concrete pairs $(\overline{\mathrm{R}} \mathrm{T}$ s for increasing distances $=1.147$,
$1.071, .992, .969$, and $.830 \mathrm{sec}$ ) than for abstract pairs $(\overline{\mathrm{R}} \mathrm{T} s=1.261,1.232,1.264,1.140,1.179)$. No such interaction occurred in the main experiment. The discrepancy deserves further investigation, but it will not be pursued here. The important generalizations from the two experiments are that pleasantness comparisons were faster for concrete- than for abstract-noun pairs, and that the symbolic distance effect occurred for both levels of concreteness, although the slope of the function may be steeper in the concrete case. Thus, the faster $\bar{R} \bar{T}$ s for concrete than abstract pairs cannot be explained in terms of confounding by meaningfulness or frequency.

\section{EXPERIMENT 2}

The second experiment involved comparisons of pictures and concrete-word pairs on the dimension of value, as defined by ratings of items in terms of their monetary worth. The experimental subjects again completed the imagery and verbal ability tests. To the extent that the comparisons rely on memory representa. tions corresponding to the referent objects rather than their names, the reaction times should again be faster with pictures than words, and faster for high-imagery than for low-imagery subjects. To the extent that verbal processes are relevant at some stage of the task, verbal ability should correlate with performance.

\section{Method}

Value ratings. The ratings were obtained from 48 university undergraduates for 147 concrete nouns which could be reasonably judged on monetary value and for which drawings of their referents were available (Paivio, Note 1). The items were listed on sheets with a space beside each item where subjects could write their judgment of the cost of the item in dollars and cents. They were instructed to round off their estimates to the nearest 10 cents for low-cost items, or the nearest dollar for more expensive items, and to the nearest $\$ 100$ for the most expensive ones. They were told to make their estimates as quickly and accurately as possible. The means of these ratings 
ranged from 8 cents for "cherry" to more than $\$ 46$ million for "rocket."

Experimental pairs. Items for the experiment were selected so that the standard deviations of the ratings were relatively low, and so that pairs sampling a wide range of value ratios could be constructed. The 10 verbal items and the corresponding pictures that were selected are shown in Table 3 along with the means and standard deviations of their rated values. The pairs were constructed by pairing every item with every other one, resulting in a list of 45 pairs in which the higher/lower value ratio ranged from 1.52 for hat : belt to 313,158 for house : new spaper. Eight random orders of each list and their left-right pair reversals resulted in a total of eight lists. The picture list corresponded to the word lists.

Procedure. The procedure was identical to that used in Experiment 1, except that the instructions were modified to be appropriate to the value dimension. That is, subjects were told to press the key on the same side as the pictured (or named) object that was more valuable in terms of monetary cost. Six practice trials with an entirely different set of items preceded the 45 experimental trials. Different groups received the picture and word pairs, with subjects alternating between the two conditions and rotating through the 16 lists in the order of their appearance in the laboratory. The subjects returned about 1 week later to complete the individual difference tests.

Subjects. Thirty-six introductory psychology students volunteered for the experiment as part of a course requirement.

\section{Results and Discussion}

The error rate ranged from $0 \%$ to $8.9 \%$ for the subjects presented with pictures, and from $0 \%$ to $13.3 \%$ for those who were presented with words. Twenty-four of the 45 pairs elicited no errors. For the remaining 21 pairs, the errors ranged from $2.8 \%$ to $27.8 \%$. The analyses were based on the correct $\bar{R} \bar{T}$ s. The individual differences data were scored as in Experiment 1, so that high- and low-ability groups resulted from a median split of standardized scores for the imagery tests and from a median split of verbal associative fluency scores.

The data were analyzed in two ways, one involving all 45 pairs as a factor and the other with the pairs grouped into six different value-ratio regions. Since the former analysis confounds value ratio with pair differences, and since the two analyses yielded the same effects at comparable significance levels, only the results of the grouped-pairs analyses are reported here. The ratio regions were selected so that each was represented by a reasonable number of pairs, specifically,

Table 3

Means and Standard Deviations of the Value Ratings for the Items Used in Experiment 2

\begin{tabular}{lrr}
\hline & \multicolumn{1}{c}{ Mean } & \multicolumn{1}{c}{ SD } \\
\hline Newspaper & .19 & .05 \\
Brush & 3.08 & 1.48 \\
Belt & 7.84 & 3.54 \\
Hat & 11.93 & 6.81 \\
Toaster & 24.05 & 8.89 \\
Bicycle & 101.56 & 32.39 \\
Stove & 449.48 & 187.29 \\
Motorcycle & $1,242.29$ & 791.23 \\
Car & $5,706.04$ & $2,285.66$ \\
House & $59,500.00$ & $22,231.73$ \\
\hline
\end{tabular}

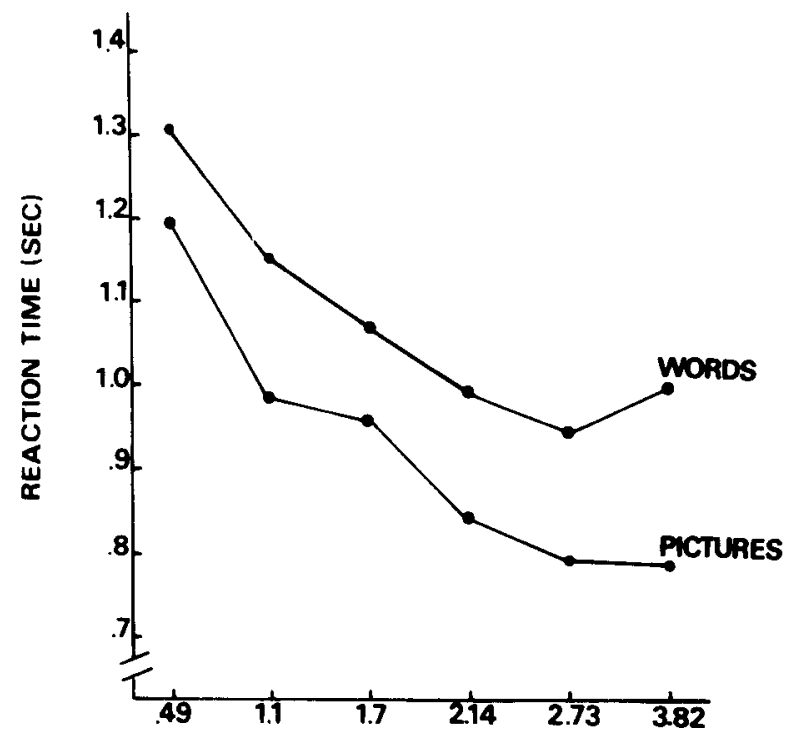

LOG RATIO VALUE DIFFERENCE

Figure 4. Mean reaction times for value comparisons for pictures and words as a function of value difference.

5-9. The ratio ranges for the regions were 14.99 , $5-19.99,20-99.99,100-399.99,400-999.99$, and 1,000 and higher. The respective mean ratios for those regions were $3.07,12.5,49.8,139,535$, and 6,538 , which correspond to logarithmic values of $.49,1.10,1.70$, $2.14,2.73$, and 3.82 . The unequal spacing even on the $\log$ scale did not present a problem because only the general shape of the symbolic distance effect was of interest.

The correct $\overline{\mathrm{R}} \overline{\mathrm{T}}$ s were analyzed by four-way analyses of variance involving stimulus mode, ratio, imagery ability, and verbal ability as factors. Value ratio was the only within-subjects factor. The significant effects are plotted in Figures 4 and 5. They show a strong symbolic distance effect $[F(5,140)=38.6, p<.001]$, faster reaction times for pictures ( $\overline{\mathrm{R}} \overline{\mathrm{T}}=921 \mathrm{msec})$ than for words $(\overline{\mathrm{R}} \overline{\mathrm{T}}=1,078 \mathrm{msec})[\mathrm{F}(1,28)=7.18, \mathrm{p}<.02]$, and faster reaction times for high-imagery $(\bar{R} \bar{T}=920 \mathrm{msec})$ than for low-imagery ( $\overline{\mathrm{R}} \overline{\mathrm{T}}=1,080 \mathrm{msec})$ subjects $[F(1,28)=7.52, p<.02]$. The imagery effect was qualified by a significant double interaction with value ratio $[F(5,140)=3.86, p<.005]$. Examination of Figure 5 indicates that the difference between high and low imagers decreased as the value difference increased.

Subjects who scored high on the verbal association test again tended to be faster than those who scored low $(\overline{\mathrm{R}} \overline{\mathrm{T}}=946$ and $1,054 \mathrm{msec})[\mathrm{F}(1,28)=3.49, \mathrm{p}=.07]$. Unlike the outcome in Experiment 1 , however, verbal ability did not enter into any significant interaction effects in this experiment (all interaction Fs $<1.0$ ).

The reliability of the main results over items and subjects is further supported by the following details. The $\bar{R} \bar{T} s$ were faster for pictures than words in the case of 42 of the 45 pairs for high-imagery subjects and 


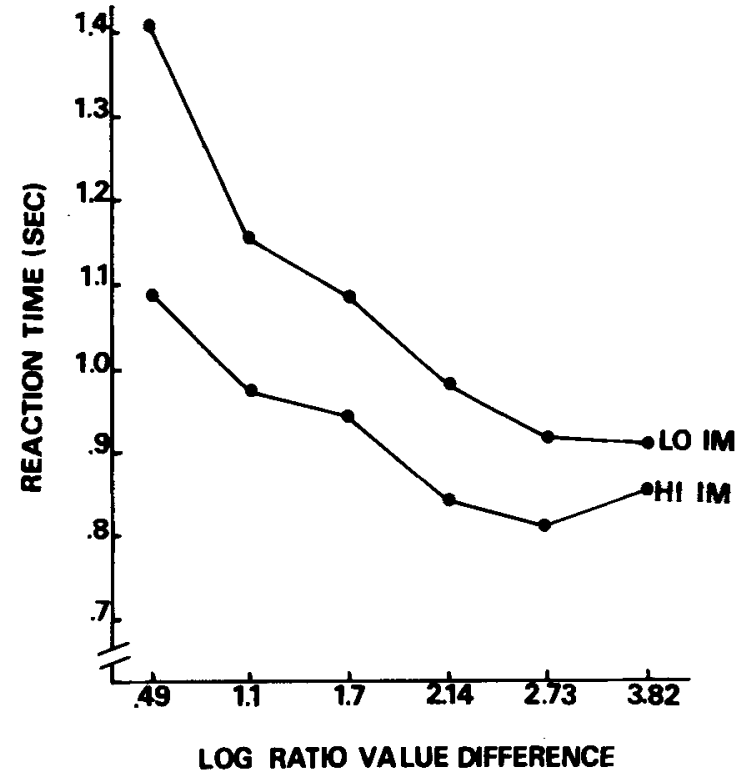

Figure 5. Mean reaction times for value comparisons for high- and low-imagery subjects as a function of value difference.

39 of the pairs for low-imagery subjects. High-imagery subjects were faster than low-imagery subjects in the case of 44 picture and 35 word pairs. All of these effects were highly significant by sign tests $(\mathrm{p}<.01)$.

The results of a Pearsonian correlational analysis again were generally consistent with those from the analysis of variance. The overall $\overline{\mathbf{R}} \overline{\mathrm{T}}$, collapsing over symbolic distance, correlated -.72 and $-.52(p \leqslant .02)$ with imagery ability for picture and word groups, respectively. The corresponding nonsignificant correlations with verbal ability were -.04 and -.28 . Note that, as in Experiment 1, the correlational trend involving verbal ability occurred only with words as stimuli.

Apart from the absence of the interaction effects involving verbal ability, the results of Experiment 2 are completely consistent with those of Experiment 1. Monetary value, like pleasantness, qualified as an abstract attribute. Nonetheless, it appears to be associated more closely with the referent objects than with their more abstract labels. This conclusion is doubly supported by convergent evidence involving faster comparison times for pictures than for words and for highthan for low-imagery subjects. ${ }^{1}$

\section{GENERAL DISCUSSION}

Several generalizations are justified by the findings. First, the typical symbolic distance effect was obtained for both pleasantness and value comparisons regardless of type of material. This observation is consistent with an analog model of mental comparisons (e.g., Griggs \& Shea, 1977; Moyer, 1973; Paivio, 1975; Potts, 1972; Holyoak \& Walker, 1976). Second, the comparisons were faster for pictures than for words in both experi- ments, and faster with concrete than with abstract words in the case of pleasantness comparisons. Third, high-imagery subjects reacted faster than did lowimagery subjects in both experiments, and this effect was relatively unqualified by type of material. The picture-word and imagery-ability results are consistent with the view that the availability of nonverbal visual representations is essential to the comparison task.

A weaker conclusion is that verbal associative ability also may be effective in these tasks, perhaps in interaction with other variables. Although the main effects of verbal ability only approached significance in each experiment, the pooled probability for the trends is highly significant $(p<.01$, assuming independence of the two experiments). The effect of verbal ability suggests that verbal processes are also involved in a somewhat stronger sense than in comparisons along concrete perceptual dimensions (Paivio, 1978). These statements are all consistent with dual-coding theory. The comparisons seem to be based on analog representations in the imagery system, which are accessed more directly with pictures than words as stimuli and by subjects with high- rather than low-imagery ability. Verbal processes obviously must contribute to task performance as well, particularly when words are involved as stimuli. In fact, the correlational analyses of both of the present experiments indicated that the suggestive negative correlation between verbal ability and reaction time occurred only when words served as stimuli.

The generalizations from the individual difference results are limited by the relatively small number of subjects and ability tests involved in the studies. This is especially true of verbal ability, which was measured only by an associational fluency test. The situation is better in the case of imagery ability, because it was measured by three tests. Moreover, confidence in the specific contribution of imagery ability is enhanced by unpublished data which showed that reaction times for high-imagery $(\bar{R} \bar{T}=1.12 \mathrm{sec})$ and low-imagery $(\overline{\mathrm{R}} \overline{\mathrm{T}}=1.14 \mathrm{sec})$ subjects did not differ in a comparison task involving a verbal attribute, namely, word (or name) familiarity (for a description of the task, see Paivio, in press-b). Thus, while more extensive research is required before strong theoretical conclusions are justified in regard to the contributions of the different abilities, the available data suggest that high-imagery ability is associated with fast reaction times specifically in those tasks where such effects would be expected on theoretical and empirical grounds, and not otherwise.

The data from the two studies are not equally con. sistent with current abstract representational theories. Interpretations in terms of relational propositions have been previously ruled out by a variety of findings (see Banks, 1977; Paivio, 1975; Holyoak \& Walker, 1976). Banks (1977) has proposed an alternative semantic coding model that can handle the symbolic distance 
effect as well as certain other findings that are not relevant here. Banks and Flora (1977) suggested, in addition, that their model can accommodate the pictureword effects, given the added assumption that the abstract semantic representations are more accessible to pictures than to words. The latter, however, is a post hoc concession to the empirical findings, since it is not predictable from the semantic coding model per se. Dual-coding theory, on the other hand, has direct (a priori) implications in regard to picture-word comparisons, which have been tested frequently. Even with its post hoc modification, Banks and Flora's model contains no assumption that accounts for the effects of individual differences in imagery ability. The combined influence of symbolic distance, picture superiority, and imagery ability in the present tasks strongly suggest that the comparison is based on information that is analog and continuous, as well as specifically nonverbal and imagistic in nature. These effects are not similarly consistent with the view that the representations are discrete and amodal (or linguistic), as the semantic coding hypothesis assumes.

The dual-coding interpretation implied above is that the analog information involved in pleasantness and value judgments is more closely associated with the image system than with the verbal system. But what, precisely, is the nature of that imagistic information? As noted earlier, it cannot be unidimensional visual information, such as size, inasmuch as those dimensions are not directly correlated with pleasantness or value. One possibility is that the analog information is "carried by" affective and motor processes that are closely associated with visual memory representations of things. Such processes presumably originate as reactions to things and persist as affective or motor memories that can be activated by pictures of the referent objects or, more indirectly, by their names when accompanied by the appropriate contextual cues. More specifically, pleasantness and value judgments might be based on continuously variable interoceptive reactions and approach or avoidance tendencies that are activated jointly by the comparison stimuli and the task instructions. The comparison stimuli provide access to the memory representations of the relevant perceptual objects, whereas the task instructions specify the associative information to be evaluated.

The hypothesis is an elaboration of a basic assumption of dual-coding theory, and it is generally consistent with certain other theoretical views as well as empirical evidence. The relevant dual-coding assumption is that symbolic and sensory modalities are orthogonal (Paivio, 1972). This means that nonverbal and verbal symbolic systems represent and process information derived from any of the sensory modalities, individually and, possibly, in parallel. Thus, imaginal representations can be viewed as integrated units that incorporate visual, auditory, motor, and affective components (Paivio, 1972). Alter- natively, they could be interpreted as involving a core representation based on form or pattern, with other attributes stored as associative information (Paivio, in press-a). Which is the more appropriate description is an empirical question. In either case, however, the implication is that the sensory-motor information associated with nonverbal objects and events is represented in the nonverbal symbolic system.

The interpretation is consistent in principle with Osgood's (e.g., Osgood \& McGuigan, 1973) view that representational meanings are derived originally from emotional and motor reactions to things, hence his designation of meaning in terms of the $r_{m}-s_{m}$ notation. The present hypothesis differs from Osgood's in the specific assumption that such response-derived information is more closely associated with nonverbal memory images of the referent objects than with their verbal representations, so that access to the affective-motor information is mediated by imaginal representations. This idea is consistent with the suggestion by Mowrer (1960, p. 171), among others, that learned emotion reactions may be mediated by a conditioned image of the unconditioned stimulus. The nonverbal nature of the association has some support from findings which indicate that the right hemisphere may have a dominant role in the processing of emotional stimuli (King \& Kimura, 1972; Schwartz, Davidson, \& Maer, 1975; Ley \& Bryden, Note 2).

The discussion has centered on the nature of analog information associated with the attributes of concrete things, but the general approach is equally relevant to more abstract representations as well as ones that are clearly verbal in nature. The relevant empirical generalization is that the symbolic distance effect can be expected for any ordered dimension (cf. Potts, 1972), however abstract or verbal it may be. It has been obtained for abstract dimensions that are difficult to conceptualize in terms of imagery, such as a time scale extending from a millisecond to a century (Holyoak \& Walker, 1976). It has also been observed for a "verbal" dimension such as word (or name) frequency (Paivio, in press-b). Such findings suggest that all ordered dimensional information is represented mentally in some analog form, perhaps based on different sensory modalities or motor systems. In the case of linguistic attributes, it is generally conceded that the representational units are discrete in the sense that phonemes, words, etc., differ from other units of the same level in an all-or-none manner. Psychologically, however, the units also have internal structure, that is, they involve stimulus and response characteristics that can vary continuously on relevant dimensions. Words, for example, can vary continuously in their length and complexity as acoustic stimuli or as responses. Thus, if words are compared on pronounceability, one would expect to obtain the distance effects characteristic of analog processes. At the same time, dual-coding theory leads to the prediction 
that comparisons on such verbal dimensions would be faster with words than with pictures, which has been confirmed (Paivio, 1975, Experiment 4). The implication is that one cannot make a sharp distinction between verbal and nonverbal representations in terms of digitalanalog (or discrete-continuous) dichotomy. In some respects, both classes of representations, or processes closely associated with them, must have analog properties; otherwise, we would have no long-term memory for the structure of either verbal or nonverbal stimuli, nor would we know how to generate them.

\section{REFERENCE NOTES}

1. Paivio, A. Unpublished list of 260 pictures and their labels with normative data on selected attributes. Department of Psychology, University of Western Ontario.

2. Ley, R. G., \& Bryden, M. P. Hemispheric differences in processing emotional stimuli. Paper presented at the Eighteenth Annual Meeting of the Psychonomic Society, 1977.

\section{REFERENCES}

Banks, W. P. Encoding and processing of symbolic information in comparative judgments. In G. H. Bower (Ed.), The psychology of learning and motivation (Vol. 11). New York: Academic Press, 1977.

Banks, W. P., \& Flora, J. Semantic and perceptual processes in symbolic comparisons. Journal of Experimental Psychology: Human Perception and Performance, 1977, 3, 278-290.

Bennett, G. K., Seashore, M. G., \& Wesman, A. G. Differential aptitude tests. New York: The Psychological Corporation, 1947.

Ernest, C. H., \& Paivio, A. Imagety ability in pairedassociate and incidental learning. Psychonomic Science, $1969,15,181-182$.

GRIGGS, R. A., \& SHEA, S. L. Integrating verbal quantitative information in linear orderings. Memory \& Cognition, 1977, 5, 287-291.

GUILFORD, J. P. The nature of human intelligence. New York: McGraw-Hill, 1967.

Holyoak, K. J., \& Walker, J. H. Subjective magnitude information in semantic orderings. Joumal of Verbal Learning and Verbal Behavior, 1976, 15, 287-299.

Kerst, S. M., \& Howard, J. H., JR. Mental comparisons for ordered information on abstract and concrete dimensions. Memory \& Cognition, 1977, 5. 227-234.

KING, F. L., \& KimURA, D. Left-ear superiority in dichotic perception of vocal nonverbal sounds. Canadian Journal of Psychology, 1972, 26, 111-116.

LIEERT, R., \& QuAsha, W. H. Revised Minnesota paper form boand test (Series AA). New York: The Psychological Corporation, 1941.
Mowrer, O. H. Leaming theory and the symbolic processe's. New York: Wiley, 1960.

MOYER, R. S. Comparing objects in memory: Evidence suggesting an internal psychophysics. Perception \& Psychophysics. $1973,13,180-184$

Osgood, C. E., \& McGuigan, F. J. Psychophysiological correlates of meaning: Essences or tracers? In F. J. McGuigan \& R. Schoonover (Eds.), The psychophysiology of thinking. New York: Academic Press. 1973.

Paivio, A. Imagery and verbal processes. New York: Holt. Rinehart, \& Winston, 1971.

Paivio, A. Symbolic and sensory modalities of memory. In M. E. Meyer (Ed.), Third western symposium on learning: Cognitive learning. Bellingham: Western Washington State College, 1972. Pp. 109-136.

Paivio, A. Perceptual comparisons through the mind's eye Memory \& Cognition, 1975, 3, 635-647.

PaIvio, A. Images, propositions, and knowledge. In J. $M$ Nicholas (Ed.), Images, perception, and knowledge. The Western Ontario Series in the Philosophy of Science. Dordrecht: Reidel, 1977.

Parvio, A. Comparisons of mental clocks. Journal of Experimental Psychology: Human Perception and Performance, 1978, 4, 61-71,

Parvio, A. Dual coding: Theoretical issues and empirical evidence. In J. M. Scandura \& C. J. Brainerd (Eds.), Structural/process models of complex human behavior. Leiden: Nordhoff, in press. (a)

PaIvio, A. Imagery, language, and semantic memory. International Journal of Psycholinguistics, in press. (b)

Paivio, A., Yuille, J. C., \& Madigan, S. A. Concreteness, imagery, and meaningfulness values for 925 nouns. Journal of Experimental Psychology, 1968, 76(1, Part 2).

Ports, G. R. Information processing strategies used in the encoding of linear orderings. Journal of Verbal Learning and Verbal Behavior, 1972, 11, 727-740.

Schwartz, G. E., Davidson, R. J., \& Maer, F. Right hemisphere lateralization for emotion in the human brain: Interactions with cognition. Science, 1975, 190, 286-288.

WINER, B. J. Statistical principles in experimental design. New York: McGraw-Hill, 1971.

\section{NOTE}

1. Mary C. Potter has also obtained faster value comparison times for pictures than for words. The experiment was reported in an address entitled "Understanding Objects and Names," presented to the Eighth Annual L.O.V.E. Conference on Perception and Cognition, Niagara Falls, Ontario, Canada, 1977.

(Received for publication July 21, 1977; revision accepted December 21, 1977.) 